\title{
PRICKLE-CELL AND BASAL-CELL SKIN CANCERS
}

H. H. HAZEN, M.D.

Professrir of Dermatology, Georgetown University, School of Medicine; Professor of Dermatology, Howard University, School of Medicine

WASHINGTON, D. C.

Although Adami ${ }^{1}$ and certain other pathologists object to a sharp differentiation of tumors arising from the superficial epithelium into prickle-cell and basalcell, it seems to me that the researches of Krompecher" and Bloodgood ${ }^{3}$ have definitely established the fact that it is possible to draw such a line, both clinically and pathologically. In spite of the numerous publications of Bloodgood and his followers, there still exists considerable confusion as to the absolutely different form of treatment that is demanded by each type, a difference necessitated by the whole course of the cancerous process. In view of certain newer forms of treatment that are springing up, and that threaten to pay no attention to either the pathology or the clinical course of these tumors, it seems wise to restate the whole question again. The therapeutic measures to which $\mathrm{I}$ have reference are the Roentgen ray, radium and the various electrical processes of fulguration, desiccation, etc.

PRECANCEROUS LESIONS

It is now generally conceded that cancers do not arise from healthy skin, but that they have their origin in either actual diseased areas or in abnormalities of some kind.

The basal-cell neoplasms frequently spring from seborrheic keratoses, recently studied by Sutton; from :ubepidermal nodules, which may be either fibro-

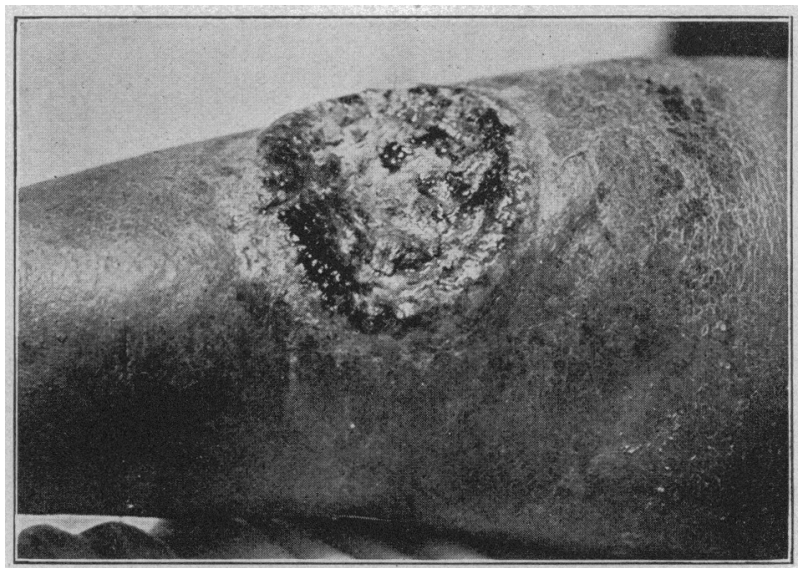

Fig. 1.-Prick:e-cell carcinoma, originating from a varicose ulce of the leg. The growtl is of six montlis' duration.

\section{HISTOGENESIS}

Petersen ${ }^{6}$ asserts that some basal-cell growths have a multicentric origin, and that they do not arise from one cell, or from one collection of cells. A recent case under my observation has borne this out, for in serial sections there were found a number of separate and distinct places where the basal cells were assuming a malignant type. This observation is very important from the point of view of treatment, for it may explain some of the frequent recurrences that take place just beyond the edge of the scar.

On the other hand, Petersen believes that the prickle-cell or squamous-cell tumors have but a single point of origin.

Basal-cell cancers most frequently arise on the face, especially from the eyelids and from the nasofacial grooves, as has been so well demonstrated by Sequeira. $^{7}$ McDonagh $^{8}$ thinks that in this location there are always many displaced epithelial cells, the remnants of some glands that existed in our ancestors, and that cancer arising in them is really an atavistic phenomenon. This variety of neoplasm is also common on the skin of the face and neck, on the scalp, and more rarely on the shoulders. It is rare on the skin of the limbs and also on the various mucous surfaces, although it does form nearly 4 per cent. of all cancers of the lip.

The prickle-cell carcinomas are most common on the mucous membranes, especially of the lip; they form the vast majority of all cancers of the extremities, and may occur anywhere on the cutaneous surfaces.

\section{APPEARANCE}

In the very earliest stages, either type of tumor mas, small sebaceous cysts, inflammatory masses in the sebaceous glands, or possibly benign epithelial growths originating in the appendages of the skin, from various other keratoses, such as those due to arsenic, or from cutaneous horns; from various overgrowths of connective tissue and epithelium, commonly but mistakenly called papillomas; and much more rarely from the lesions produced by lupus, syphilis, psoriasis and blastomycosis; and from leg ulcers or sinuses of various kinds.

On the other hand, prickle-cell cancers do not often originate from seborrheic keratoses, unless they be situated on the hands, but do arise from either arsenical or Roentgen-ray keratoses. They also arise from scars which are due to burns or to wounds which have healed by granulation, occasionally from sinuses of osteomyelitis, mastoid disease, etc.; from leg ulcers; from wens, and from various other chronic dermatoses. Bloodgood's papers ${ }^{5}$ give a very good idea of these lesions.

\footnotetext{
1. Adami: Principles of Pathology, New York, 1908, i, 735.

2. Krompecher: Der Basalzellenkrebs, Jena, Fischer, 1903

3. Bloodgond: Progr. Med., December, 1904, 136.

4. Sutton, R. L.: The Symptomatology and Treatment of Seborrheic Keratoses, THE Journal A. M. A., Jan. 30, 1915, p. 403.

5. Published in Progressive Medicine.
}

first manifests itself as a cutaneous or subcutaneous nodule, that speedily forms an indurated ulcer, covered by a crust. When this crust is removed there may be either serous discharge or bleeding. At this stage physical examination alone cannot tell the variety of cancer, although the history and the location will usually give more than an inkling. However, the prickle-cell neoplasms usually grow much more rapidly, and the induration is deep. The surface of a fully developed squamous-cell cancer is often more or less verrucose, while the surface of a basal-cell growth is comparatively smooth. In the typical basal-cell growths there is more or less of a rolled edge, and individual pearly nodules can often be distinguished. In addition, there may be a certain amount of spontaneous healing, as evidenced by scar formation; this never exists in prickle-cell neoplasms. In general, however, either variety may be ulcerative or fungous, according to the resistance of the underlying tissue that the cancer cells are called on to penetrate. Both kinds may invade bone and periosteum; this is not a distinguishing mark of the prickle-cell variety.

6. Petersen: Beitr. z. klin. Chir., 1902, xxxii, 543.

7. Sequeira: Brit. Jour. Dermatol., 1913, xxv, 172

8. McDonagh: Brit. Jour. Dermatol., 1912, xxiv, 291. 


\section{METASTASES}

Basal-cell growths never metastasize. I am fully aware that this statement will at once arcuse opposition, but it is nevertheless true. It must be admitted, however, that a basal-cell growth can becom 2 changed into the prickle-cell variety and metastasis then result. Also, there is still a third form of cutaneous tumor, the cuboid cell, which springs from the transitional epithelium placed between the basal cells and the prickle cells of the rete. Microscopically these tumors closely resemble the basal-cell group, but metastases from them are common. These two facts explain the cases of reported metastases from the basal-cell cancers.

On the other hand, ihe pricklecell carcinomas nearly always metastasize to the regional lymphatics; although this may not take place until the tumor has existed for a number of years. Also the original growth may be removed and the metastases not manifest themselves until a long time has passed. It should always be borne in mind that cancer cells can lie latent for many months. As a result, one must not say that a case of cancer is permanently cured until a long time has elapsed, probably at least eight years.

\section{PATHOLOGY}

Gross.-When a prickle-cell cancer is excised and cut through, three things are to be noticed: first, that the surface is rough; second, that the infiltration is deep; third, that the cancerous alveoli radiate downward in the form of white lines, about the size of a very fine thread. In a basal-cell tumor the surface is usually comparatively smooth, the invasion less extensive, and the alveoli much smaller, in fact, often indistinguishable.

Microscopic.-When a section from a prickle-cell carcinoma is stained with hematoxylin and eosin, or with a similar combination of acid and basic dyes, it is noted that the cancerous alveoli are large, and that there is a great tendency for whorl formation to occur. These whorls are very apt to result in epithelial pearls. In addition, the individual cells are large and stain intensely with the acid dyes.

In the basal-cell neoplasms, the alveoli are usually small, if the growth has existed for any length of time, and there are never any whorls or pearls present. The individual cells are small, and stain with the basic dye rather than with the acid one.

There should be little difficulty in distinguishing the two varieties, except when the cells have become sepa- rated, and are individually invading the tissues after the manner of a scirthus carcinoma. Even then, in some fields, typical arrangements can be found.

\section{DIAGNOSIS}

In early cases it is frequently impossible to tell one variety of tumor from the other, except by the location on which it develops, and by the history of the precancerous lesion from which it sprang. $\mathrm{Ne}-$ oplasms of the skin of the face are usually of the milder type--basal-cell, while cancers of the lips, penis and limbs are almost invariably derived from the squamous portion of the epithelium. Tumors of the upper portion of the trunk are usually basal-cell, while of the lower portion the reverse is true, the dangerous ones being the more common.

As already pointed out, growths springing from ulcers, sinuses, s c a rs, Roentgen-ray burns or keratoses, lupus and other active skin lesions are more apt to be prickle-cell, while the growths originating from seborrheic keratoses of the face. and from subepidermal nodules, are often basal-cell.

In later cases the same factors play an important part in the diagnosis, but new ones enter the field. The rapidity with which growth occurs is of great importance, for basal-cell neoplasms usually grow slowly, much more slowly than the other type. A verrucose surface points toward the cancer being prickle-cell, while a smooth surface favors the other

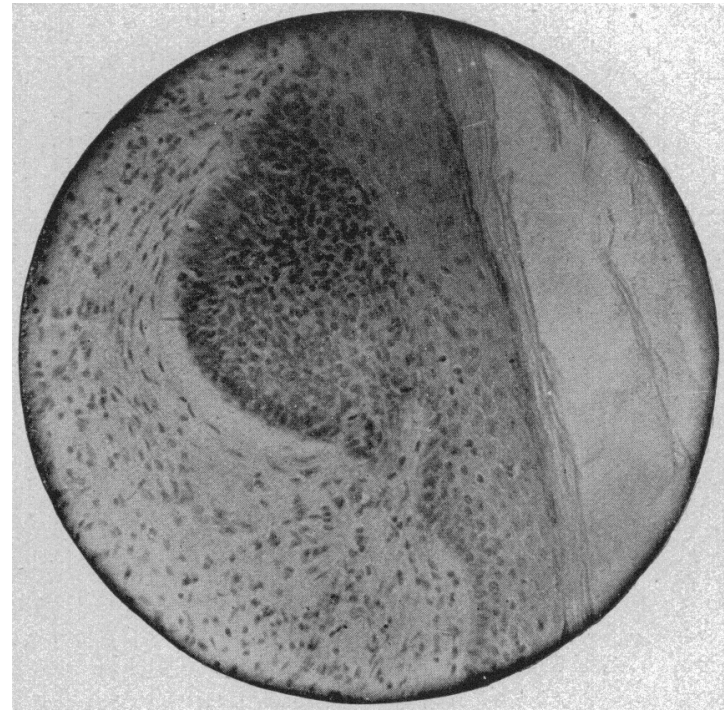

Fig. 3.-An unusually early basal-cell carcinoma, showing the point of origin very well. ype. The depth of the induration is also an imporiant factor, beirg much greater in the more malignant neoplasms. The presence of spontaneously healed areas, o: the occurrence of definite small pearly nodules at the edges, is strongly indicative of a basal-cell origin. The presence of enlargement of the regional glands does not make the diagnosis of squamouscell cancer certain, for the glands may enlarge as the result of the absorption of inflammatory products.

Under no circumstances should a section of the growth be removed for diagnosis by a simple incision, for such a procedure leaves the blood vessels and lymphatics gaping and favors the dissemination of the cancerous process, inasmuch as malignant cells can readily enter the circulation. If it is deemed absolutely necessary to remove a bit, this should be done with the actual cautery, or with an old knife that has been flamed to a dull red heat. However, it is much better to remove the whole growth, and make the diagnosis from that. A skilful pathologist can usually 
make his diagnosis from the appearance of the gross specimen.

\section{PROGNOSIS}

Basal-cell tumors are apt to last for years; they may grow so as to cover a very wide area, and kill only when they erode a large vessel, or when they invade the meninges. The patient is much more apt to die from secondary infection. On the other hand, the prickle-cell neoplasms cause metastases and thus kill directly.

\section{TREATMENT}

Three classes of growths must be considered, first those that are frankly basal-cell; second, those that are unmistakably prickle-cell, and third, those concerning which there is some doubt.

A basal-cell cancer can be permanently cured if it is completely removed locally, for metastases do not occur. This complete local removal, however, is not always a simple undertaking, for a study of the pathology will show that they frequently undercut the epidermis to a considerable extent, so that the presence of extensive involvement is not realized. Secondly, they may be multicentric in origin, so that there may be new areas in the neighborhood.

There are many ways of removing a cancer, the knife, the calttery, the curet combined with the later application of a caustic, caustic paste, the Roentgen ray, radium, fulguration, desiccation, etc.

When one searches the literature for reports of late results in a long series of cases, he is forced to the conclusion that surgery yields the best results, for those practicing the other methods have not shown what they can permanently accomplish. Of course there are one or two individual exceptions, but as a general proposition $\mathrm{th}$ is statement must hold.

In the surgical pathologic department of the Johns Hopkins Hospital, it has been found that nearly 50 per cent. of the patients who are suffering from late cancer give a history of early treatment with caustic pastes, and that many more have had Roentgenray treatment, etc. mal epithelium.

The Roentgen ray has probably failed because too soft a tube was employed, a tube that did not give off rays of sufficient penetration. It is well known that such treatment can cause healing to take place on the surface, while in the depths the cancer spreads

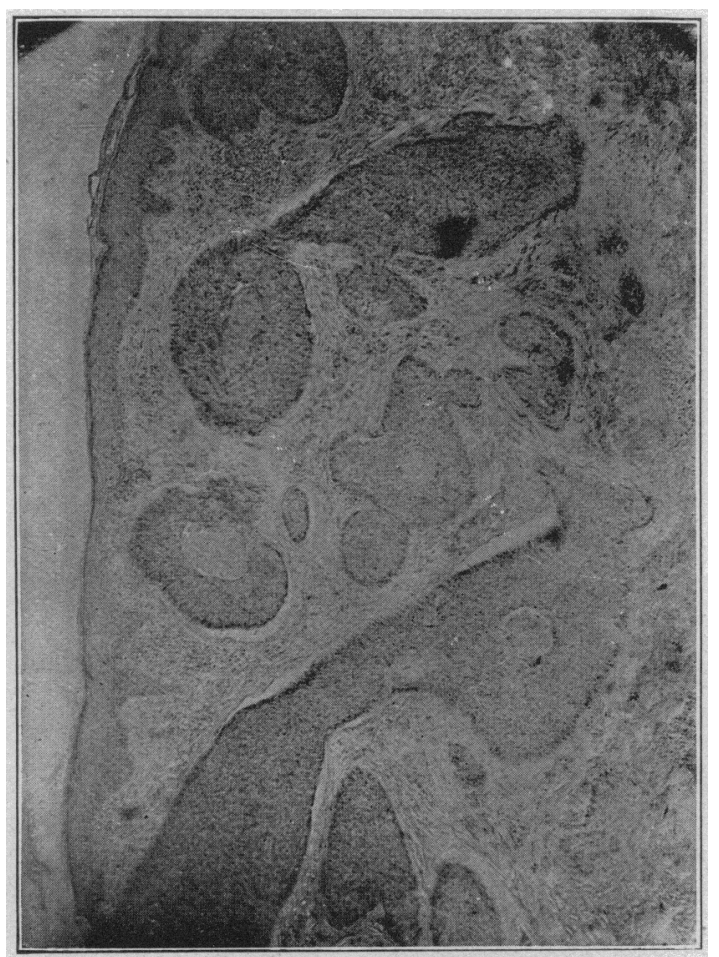

Fig. 4,-The later cievelopment of a basal-cell cancer. In this case superficial healing had been produced by the Roentgen ray, but the cancer was spreading beneath nor-

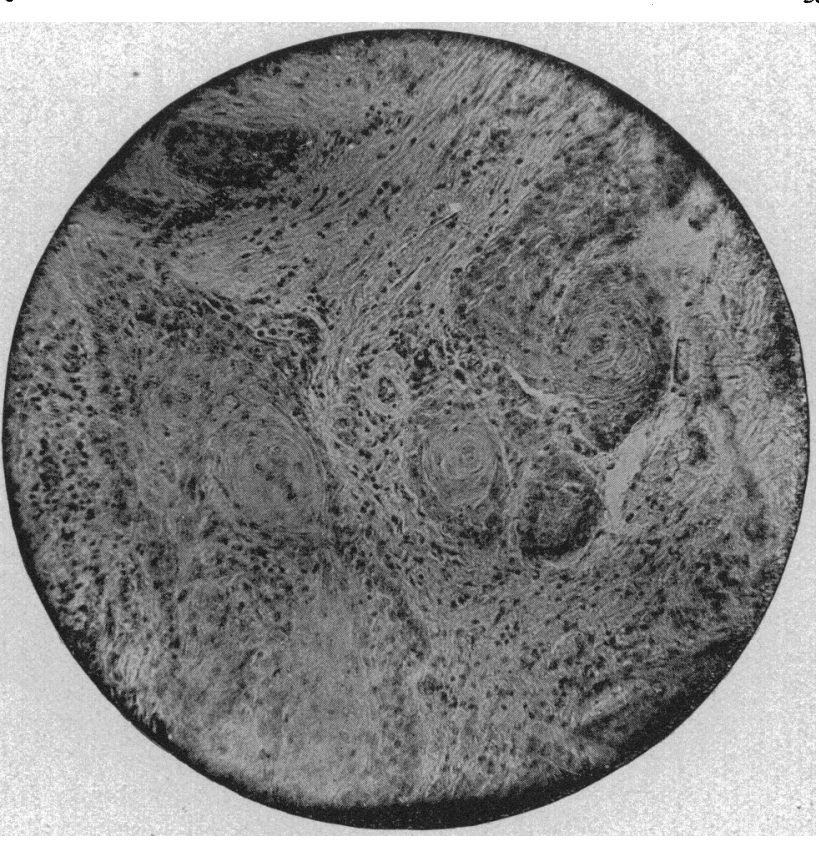
Fig. 5.-A typical section from a prickle-cell cancer. Notice
the whorl formation. takes place only at the original site, and in the draining glands. Hence it is fairly safe to remove both the tumor and the glands, leaving the connecting lymphatics undisturbed. If recurrence should take place in them, removal is possi- 
ble. If the glands are left undisturbed, cancer cells may pass through them, and form internal metastatic growths. In other words, by removing the glands we have a fairly sure way of limiting the growth.

In dealing with the uncertain cases we should always bear in mind that the first essential is to make an accurate diagnosis; hence, for the removal of such growths, a measure should be adopted that will permit of their safe recognition. This means that only the knife or actual cautery should be employed. In order to do the best work, these tumors should be diagnosed at once. A trained pathologist can usually do this satisfactorily by means of a careful examination of the gross specimen, but in many cases a frozen section should be made at once, and if the growth is of the prickle-cell type, the glands removed at the same sitting. In dealing with the very early cancers, growths that have not existed for more than a month, it is probable that local operation alone will suffice.

\section{THE CLASSIFICATION OF MEDICAL SCHOOLS *}

HENRY S. PRITCHETT, Ph.D.

President, Carnegie Foundation for the Advancement of Teaching NEW YORK

The desire to classify seems to be a universal human motive. In education, in politics, in society, men reach out for some form of classification that shall be definite and specific, so that every cause may have its right label, every party its true name, and every instithition be included in its proper class.

Institutions as they develop become more complex, and hence more difficult to divide into classes. These difficulties increase as one seeks to take into account intellectual and moral qualities. For this reason it has been almost impossible to classify colleges. It would be easy enough, indeed, to separate colleges into groups according to some simple condition, for example, those having more than five hundred students, or more than a million dollars endowment, or those teaching Hebrew ; but such groupings would have little significance. The moment one takes into account intellectual qualities and educational facilities, the groups fade into each other by imperceptible gradations so as to wipe out the lines of demarcation.

The classification of medical schools does not present quite the same difficulties. There are certain criteria that may be applied to them, or, indeed, to technical and professional schools of any sort, which are more definite and easier to appraise than is the case with colleges.

Before any suggestions can be offered, it is necessary to present some review of the work of the Council on Medical Education of the American Medical Association, which has for some years been engaged in just this effort. Moreover, it has achieved notable results in the improvement of medical education in the United States. It has done more than any other agency could have done to weed out unfit medical schools, encourage full-time professors in the scientific branches, to demand bedside clinical teaching, and insist on adequate laboratory and hospital facilities.

* Read at the joint meeting of the Association of American Medical Colleges and the Federation of State Medical Boards, Chicago, Feb. 17 1915. The full discussion of this paper appears under Society Proceedings, this issue.
This the Council has been able to do not only on account of the hard work of its chairman and members, but also because it represents the medical profession in America. Over half the practitioners of the country are members of the local medical societies. These choose delegates to the state societies, and the latter in turn choose the House of Delegates, a body of approximately one hundred and fifty. The Council on Medical Education is a committee of this body, and its action has all the weight of the entire medical profession. Universities, colleges and state boards have accepted the decision of the Council as the expression of the thought of the leaders of the profession in America.

Under these conditions the reorganization of medical teaching has advanced very rapidly, and the classifications of the Council have now become sufficiently differentiated to make some examination of the present situation desirable to all interested in medicine and in medical education.

As a layman in medicine I venture to make such a review because the Council is primarily a council on education, not on medicine. It is in effect a national agency in education, and its work touches the secondary school, the college, the university, no less directly than the medical school. It has dealt quite as much with the education which precedes the medical school as with that given in it. It is impossible, indeed, to legislate on medical education without becoming immediately involved in the entire educational problem.

From the standpoint of education I have not found myself in agreement with all of the work the Council has done, admirable as it is. For example, I cannot make myself believe that to begin three sciences and a modern language in one year will make toward sound education and training. I am sure that this recommendation will in the end be only a step toward a more wholesome effort to present medical candidates who are at the same time fairly educated and who are grounded in the elements of these sciences.

For similar reasons I look on the enforcement of this provision over the whole United States as premature. In the South the medical schools were barely on the high school basis, and I fear the effect of this action both on medical school and on high school. It will, I fear, work to continue for some years a series of insincere adjustments; and the progress made in the raising of standards, while attractive on paper, is liable to be in part illusory.

One feature of this effort for which the Council is not responsible is the submedical school teaching elementary science and modern languages. For these parasites on our educational system there is no excuse.

If the colleges are not doing rightly the work of premedical education, the remedy is to turn back unprepared students to them and to see that their work is well done. The remedy does not lie in having the medical school take over the work of the college. The real purpose of these schools is to get students. To be consistent, the medical board which goes into this effort should add a preparatory school as well. The intake would be larger. One can forgive in a measure the resort to this device in the case of a detached medical school, living on fees and with starvation ahead as a result of the new entrance conditions; but for a university to maintain, in addition to its own schools, such an extramural device for catching students seems unworthy of a university. 